\title{
The Quality of a Traditional Dietary Pattern in Relation to Metabolic Syndrome in Elderly South Koreans
}

\author{
Chorong Oh, Jaekyung No* \\ Department of Food and Nutrition, Kyungsung University, Busan, Korea
}

Background: The most beneficial dietary pattern in managing metabolic syndrome (MetS) in the elderly has not been ascertained. The aim of this study is to classify dietary patterns and to examine associations between dietary pattern, MetS and body composition in elderly Koreans.

Methods: This study was conducted among Koreans 65 years or older using data from the Korea National Health and Nutrition Examination Survey in 2009. A total of 1,567 study subjects were included. All statistical analyses were conducted using SPSS version 20.0 and dietary patterns were classified by cluster analysis.

Results: There were three dietary patterns derived by cluster analysis in this study. We observed that most South Korean elderly still maintain a traditional dietary pattern. Dietary patterns were classified as balanced $(31 \%)$, imbalanced $(40 \%)$, or very imbalanced (30\%), with the majority of subjects having an unbalanced diet pattern in which their total energy and nutrient intake was insufficient compared with the Dietary Reference Intake for Koreans. Those in the very imbalanced group had a ratio of macronutrients (carbohydrates:fats:protein) of 81.15:7.18:11.50 and a 54\% higher likelihood of having hypertriglyceridemia $(P=0.025)$ compared with those in the balanced group.

Conclusion: The current findings indicate that the diets of South Korean elderly are nutritionally imbalanced, including high carbohydrate consumption, which confers a high risk hypertriglyceridemia. These findings highlight the effect of nutritional imbalance in elderly with MetS.

Key words: Dietary pattern, Metabolic syndrome, Nutrient, Korean elderly, Korea National Health and Nutrition Examination Survey 2009

\author{
Received January 8, 2018 \\ Reviewed March 6, 2018 \\ Accepted November 19, 2018 \\ ${ }^{*}$ Corresponding author \\ Jaekyung No \\ https://orcid.org/0000-0003-2433-346X \\ Department of Food and Nutrition, \\ Kyungsung University, 309 Suyeong-ro, \\ Nam-gu, Busan 48434, Korea \\ Tel: +82-51-663-4651 \\ Fax: +82-51-663-4651 \\ E-mail:jkno3@ks.ac.kr
}

\section{INTRODUCTION}

Metabolic abnormalities play a role in the development of chronic disease and have been linked with a cluster of cardiovascular risk factors and body composition changes called sarcopenia in aging. ${ }^{1-3}$ Additional factors associated with metabolic abnormalities are insulin resistance (IR) and chronic low-grade inflammation. ${ }^{4}$ For this reason, much research on the metabolic syndrome (MetS) and nutrition focused on intake of carbohydrates and fat. The recent discovery that loss of muscle mass aggravated IR and is associated with an increased incidence of the MetS; many studies considered protein intake recommended by the Dietary Reference Intake for Koreans (KDRIs), which resulted in the loss of muscle in the elderly. ${ }^{5}$ Many researchers have discussed the limitations of studies identifying correlations between single nutrients and chronic diseases because food comprises multiple nutrients and their interactions must be considered. ${ }^{6}$ Thus, a dietary pattern approach has been used to measure the total usual intake of food combinations and general food intake quality.

It is very important to study not only the paradigm shift from

Copyright $\odot 2018$ Korean Society for the Study of Obesity

(a) This is an Open Access article distributed under the terms of the Creative Commons Attribution Non-Commercial License (http://creativecommons.org/licenses/by-nc/4.0/) which permits unrestricted non-commercial use, distribution, and reproduction in any medium, provided the original work is properly cited. 
nutrient research to diet pattern research, but also the characteristics of each country's diet patterns. Unique dietary patterns may influence the prevalence of chronic diseases. ${ }^{7}$ Dietary patterns of South Koreans differ from those of Westerners. Generally, a traditional Korean diet is considered healthier than a Westernized diet. However, several studies showed that elderly South Koreans have a low intake of major nutrients, and as age increases, nutritional status worsens. ${ }^{8}$ In one study, the prevalence of nutritional deficiency was higher in women, rural residents, and the lowest income group. From an epigenetics perspective, lifestyle, nutrient intake and environment could result in DNA changes. ${ }^{10,11}$ Dietary pattern studies have become key tools in the search for ways to prevent MetS.

Several studies have focused on the dietary habits and nutritional status of elderly South Koreans ${ }^{12-14}$, but few studies have compared Korean dietary patterns and their role in MetS in elderly South Koreans. ${ }^{15}$ The principal objective of this study is to assess dietary patterns among elderly South Koreans in an effort to determine whether dietary interventions may be an opportunity for prevention of MetS in this population.

\section{METHODS}

\section{Study subjects}

The data for this study was obtained from the nationally representative survey, Korea National Health and Nutrition Examination Survey (KNHANES) in 2009. It was conducted by the Korea Centers for Disease Control and Prevention (KCDC). Among 1,788 eligible subjects aged 65 or older who participated in a health interview survey, health examination survey, and nutrition survey, we excluded subjects $(n=194)$ for whom there was incomplete information including, health related variables and dietary intake data. In addition, we excluded those $(n=27)$ who reported implausibly low or high daily energy intake ( $<500$ or $>5,000 \mathrm{kcal} /$ day). The final sample included 1,567 elderly persons (651 men and 916 women). This study protocol was provided by the KCDC, and all subjects participated voluntarily. This study was approved with written informed consent from each subject (No. 2009-01CON-03-2C).

\section{Assessment of dietary patterns}

Food items were categorized into 23 food groups by modifying the 18 common food groups in the Korean nutrient database. Grains such as white rice, brown rice, and their products are a major energy source and staple food in the Korean diet. Almost half of the daily energy intake was from grains among our study subjects; therefore, grains and their products were further divided into six subgroups: white rice, brown rice, other grains, noodles and dumplings, and flour and bread, pizza and hamburgers. Kimchi was separated into a single food group from the vegetable group ${ }^{16,17}$ because it is traditionally served as a single side dish. Table 1 shows the 22 food groups categories used in the cluster analysis that enabled us to directly compare distinct groups. There are various methods of analyzing dietary patterns, such as factor analysis, which detects a dietary pattern by finding correlated dietary factors, and cluster analysis, which classifies individuals into distinct groups by relatively homogeneous factors. We used the K-means method, which is based on Euclidean distances and conducted repeatedly to evaluate

Table 1. Food group (\% energy) by dietary pattern among elderly South Koreans

\begin{tabular}{|c|c|c|c|c|}
\hline Variable & $\begin{array}{c}\text { Balanced } \\
\text { pattern }(n=497)\end{array}$ & $\begin{array}{c}\text { Imbalanced } \\
\text { pattern }(n=642)\end{array}$ & $\begin{array}{l}\text { Very imbalanced } \\
\text { pattern }(n=483)\end{array}$ & $P^{*}$ \\
\hline White rice & $35.74^{\dagger} \pm 0.66$ & $56.63 \pm 0.38$ & $78.95 \pm 0.44$ & $<0.001$ \\
\hline Other grains & $6.09 \pm 0.45$ & $7.33 \pm 0.51$ & $5.72 \pm 0.36$ & 0.032 \\
\hline Brown rice & $7.44 \pm 1.11$ & $5.85 \pm 0.74$ & $3.84 \pm 0.60$ & 0.027 \\
\hline Flour · bread & $9.74 \pm 1.03$ & $6.94 \pm 0.77$ & $3.55 \pm 0.50$ & $<0.001$ \\
\hline Noodles · dumplings & $22.51 \pm 1.18$ & $16.23 \pm 1.23$ & $9.57 \pm 3.33$ & $<0.001$ \\
\hline Potatoes & $8.48 \pm 0.99$ & $5.70 \pm 0.58$ & $3.69 \pm 0.62$ & $<0.001$ \\
\hline Sugar. sweets & $2.30 \pm 0.28$ & $2.40 \pm 0.17$ & $1.36 \pm 0.16$ & 0.001 \\
\hline Legumes & $5.46 \pm 0.42$ & $5.33 \pm 0.31$ & $4.75 \pm 0.37$ & 0.381 \\
\hline Nuts & $1.62 \pm 0.30$ & $0.85 \pm 0.10$ & $0.62 \pm 0.12$ & 0.010 \\
\hline Vegetables & $3.12 \pm 0.14$ & $3.06 \pm 0.13$ & $2.31 \pm 0.14$ & $<0.001$ \\
\hline Kimchi & $1.53 \pm 0.08$ & $1.82 \pm 0.08$ & $1.90 \pm 0.14$ & 0.018 \\
\hline Mushrooms & $0.33 \pm 0.03$ & $0.33 \pm 0.04$ & $0.37 \pm 0.15$ & 0.964 \\
\hline Fruits & $18.41 \pm 1.10$ & $13.89 \pm 0.62$ & $7.67 \pm 0.53$ & $<0.001$ \\
\hline Meat - meat products & $9.34 \pm 0.67$ & $8.00 \pm 0.49$ & $5.28 \pm 0.36$ & $<0.001$ \\
\hline Eggs & $2.70 \pm 0.18$ & $2.92 \pm 0.22$ & $2.53 \pm 0.27$ & 0.557 \\
\hline Fish & $3.78 \pm 0.30$ & $3.61 \pm 0.30$ & $2.45 \pm 0.24$ & $<0.001$ \\
\hline Seaweed & $0.97 \pm 0.10$ & $1.29 \pm 0.11$ & $1.25 \pm 0.11$ & 0.053 \\
\hline Milk. dairy products & $13.81 \pm 1.19$ & $8.6 \pm 0.55$ & $7.61 \pm 1.05$ & $<0.001$ \\
\hline Oils & $2.70 \pm 0.16$ & $2.25 \pm 0.13$ & $1.39 \pm 0.14$ & $<0.001$ \\
\hline Beverages & $3.64 \pm 0.29$ & $3.82 \pm 0.23$ & $4.63 \pm 0.50$ & 0.238 \\
\hline Alcohols & $17.65 \pm 2.09$ & $10.96 \pm 0.99$ & $5.45 \pm 1.03$ & $<0.001$ \\
\hline Seasoning & $2.55 \pm 1.96$ & $2.39 \pm 0.17$ & $1.86 \pm 0.16$ & 0.008 \\
\hline
\end{tabular}

Values are presented as mean \pm standard deviation.

${ }^{*}$ P-value was obtained from a multivariate linear regression model after adjusting for age, gender, region, income, and education level; ${ }^{\dagger}$ Mean percent energy intake from each food group by cluster analysis using data from Korea National Health and Nutrition Examination Survey. 
the stability of the clusters. After prior analysis, three different clusters were identified and the participants were reassigned to the nearest cluster. This analysis separated individuals into maximally different dietary patterns based on the actual food intake of the population and the percentage of total energy intake from each food group. Several previous studies found that classification into two or three different patterns (clusters) was most suitable for analysis. ${ }^{16,18}$ In the present study, dietary patterns were classified into three different groups (T1, T2, T3) by cluster analysis using the Kmeans algorithm and given descriptive names.

\section{Assessment of MetS}

We used the following criteria to define metabolic risk factors: central obesity (waist circumference $\geq 90 \mathrm{~cm}$ in men and $\geq 85 \mathrm{~cm}$ in women), hypertriglyceridemia (blood triglyceride [TG] level $\geq 150 \mathrm{mg} / \mathrm{dL}$ ), hyperglycemia (fasting plasma glucose $\geq 100 \mathrm{mg} / \mathrm{dL}$ ), and high-density lipoprotein (HDL) cholesterol ( $\geq 40 \mathrm{mg} / \mathrm{dL}$ in men and $\geq 50 \mathrm{mg} / \mathrm{dL}$ in women). Elevated blood pressure as defined by systolic blood pressure $\geq 130 \mathrm{mmHg}$ or diastolic blood pressure $\geq 85 \mathrm{mmHg}$. Homeostasis model assessment of IR was calculated by fasting insulin $(\mu \mathrm{IU} / \mathrm{mL}) \times$ fasting plasma glucose $(\mathrm{mg} / \mathrm{dL}) / 405$. Blood pressure was measured by standard methods, using a sphygmomanometer with the subject in a sitting position. Three measurements were taken on all subjects at 5-minute intervals, and the average of the second and third measurements was used in the analysis. Blood samples were collected in the morning after having fasted for at least 8 hours. Fasting glucose, total cholesterol, and TGs were analyzed in a central, certified laboratory.

\section{Statistical analysis}

Statistical analyses were performed using IBM SPSS version 20.0 (IBM Corp., Armonk, NY, USA). Dietary patterns were derived by cluster analysis using the K-means algorithm. Cluster analysis is commonly used to classify individuals into relatively homogeneous groups using the K-means algorithm. Thus, unlike factor analysis, it is used to directly compare distinct groups. The number of clusters was determined using a dendrogram procedure. Three groups were selected to represent the dietary patterns of elderly Koreans. A generalized linear model was used to test for significant differences in mean values of biochemical parameters, anthropometric parame- ters, and nutrient intake among the dietary pattern groups. Logistic regression was used to calculate odds ratios (ORs) with 95\% confidence intervals (CIs) for MetS and dietary patterns. All models were adjusted for age, gender, education, smoking, and physical activity. Statistical significance was accepted at $P<0.05$.

\section{RESULTS}

Table 1 shows food groups (\% energy) by dietary patterns. The three different patterns differed based on nutritional balance ( $\mathrm{T} 1$, T2, and T3). Thirty-one percent of subjects were assigned to the $\mathrm{T} 1$ pattern, in which white rice consumption accounted for $35.74 \%$ of total intake with $9.34 \%$ from meat, $17.65 \%$ from alcohol, 9.43\% from pizza, $9.73 \%$ from flours, $22.51 \%$ from noodles, and $13.81 \%$ from dairy products. With the exception of kimchi, seaweed and white rice, the intake of most foods was higher in the $\mathrm{T} 1$ group than the others. Thus, we named $\mathrm{T} 1$ the balanced pattern. This pattern was characterized by the consumption of a variety of food groups such as other grains, fruit, eggs, fish and milk and appropriate percent ratios of energy intake from the three macronutrients (55\%-70\%:15\%-25\%:15\%-20\%) compared to the KDRIs. The $\mathrm{T} 2$ or imbalanced pattern comprised $40 \%$ of subjects. This group had more than half of its energy intake from white rice in addition to consuming traditional Korean foods such as vegetables, kimchi, eggs, legumes, seaweed, but no Westernized foods such as pizza and hamburgers. The remaining $31 \%$ of subjects were assigned to the $\mathrm{T} 3$ or very imbalanced pattern. With the exception of white rice and kimchi, most of this group's food intake was imbalanced compared to the other two patterns.

Mean nutrient intakes by dietary patterns are presented in Table 2 . There were significant differences in nutrient intake among the three groups with the exception of carbohydrates and vitamin D. Energy intake was significantly different among the dietary patterns, and the balanced pattern had the highest intake $(1,745.09 \pm 51.57$ vs. $1,585.57 \pm 35.96$ vs. $1,559.29 \pm 46.43 \mathrm{kcal} /$ day). Carbohydrate intake was not significantly different $(291.14 \pm 8.58$ vs. $293.43 \pm$ 5.91 vs. $310.26 \pm 8.55 \mathrm{~g} /$ day). Protein intake was sufficient compared with KDRIs in the balanced $(1.05 \pm 0.03 \mathrm{~g} / \mathrm{kg} /$ day $)$ and imbalanced $(0.92 \pm 0.02 \mathrm{~g} / \mathrm{kg} /$ day $)$ groups, but deficient in the very imbalanced group $(0.78 \pm 0.03 \mathrm{~g} / \mathrm{kg} /$ day $)$. Fat intake was low in all 
Table 2. Comparison of nutrient intake by dietary pattern

\begin{tabular}{|c|c|c|c|c|}
\hline Variable & $\begin{array}{l}\text { Balanced pattern } \\
\qquad(\mathrm{n}=497)\end{array}$ & $\begin{array}{c}\text { Imbalanced } \\
\text { pattern }(n=642)\end{array}$ & $\begin{array}{l}\text { Very imbalanced } \\
\text { pattern }(n=483)\end{array}$ & $P^{*}$ \\
\hline Energy (kcal/day) & $1,745.09 \pm 51.57$ & $1,585.57 \pm 35.96$ & $1,559.29 \pm 46.43$ & 0.003 \\
\hline Energy $(/ \mathrm{kg})$ & $28.94 \pm 0.83$ & $26.44 \pm 0.6$ & $26.68 \pm 0.83$ & 0.011 \\
\hline $\begin{array}{c}\text { Carbohydrate } \\
\text { energy (\%) }\end{array}$ & $68.58 \pm 0.79$ & $75.25 \pm 0.55$ & $81.15 \pm 0.58$ & $<0.001$ \\
\hline Fat energy (\%) & $16.33 \pm 0.45$ & $11.61 \pm 0.33$ & $7.18 \pm 0.39$ & $<0.001$ \\
\hline Protein energy (\%) & $14.55 \pm 0.2$ & $13.73 \pm 0.21$ & $11.50 \pm 0.21$ & $<0.001$ \\
\hline Protein (g/day) & $63.6 \pm 1.92$ & $55.51 \pm 1.56$ & $46.47 \pm 1.69$ & $<0.001$ \\
\hline Protein (g/kg/day) & $1.05 \pm 0.03$ & $0.92 \pm 0.02$ & $0.78 \pm 0.03$ & $<0.001$ \\
\hline $\begin{array}{l}\text { Carbohydrate } \\
\text { (g/day) }\end{array}$ & $291.14 \pm 8.58$ & $293.43 \pm 5.91$ & $310.26 \pm 8.55$ & 0.105 \\
\hline Fat (g/day) & $32.32 \pm 1.51$ & $21.38 \pm 0.96$ & $13.98 \pm 0.98$ & $<0.001$ \\
\hline Calcium (mg/day) & $510.58 \pm 21.17$ & $496.15 \pm 45.23$ & $340.18 \pm 23.75$ & $<0.001$ \\
\hline $\begin{array}{l}\text { Phosphorus } \\
\text { (mg/day) }\end{array}$ & $1,114.39 \pm 35.16$ & $1,019.03 \pm 25.37$ & $899.62 \pm 29.02$ & $<0.001$ \\
\hline Iron (mg/day) & $16.41 \pm 1.18$ & $15.1 \pm 1.08$ & $10.86 \pm 0.83$ & $<0.001$ \\
\hline Sodium (mg/day) & $4,590.67 \pm 218.57$ & $4,199.19 \pm 199.99$ & $3,504.07 \pm 229.69$ & $<0.001$ \\
\hline $\begin{array}{l}\text { Potassium } \\
\text { (mg/day) }\end{array}$ & $3,179.98 \pm 97.97$ & $2,689.41 \pm 76.11$ & $2,130.66 \pm 87.89$ & $<0.001$ \\
\hline $\begin{array}{l}\text { Vitamin A } \\
\text { ( } \mu \mathrm{g} R E / \text { day) }\end{array}$ & $912.24 \pm 79.1$ & $701.87 \pm 59.23$ & $529.47 \pm 65.23$ & $<0.001$ \\
\hline $\begin{array}{l}\text { Vitamin C } \\
\text { (mg/day) }\end{array}$ & $110.62 \pm 5.45$ & $90.58 \pm 4.46$ & $64.45 \pm 5.08$ & $<0.001$ \\
\hline Vitamin D (ng/mL) & $19.23 \pm 0.6$ & $18.44 \pm 0.55$ & $18.22 \pm 0.74$ & 0.314 \\
\hline Carotene ( $\mu \mathrm{g} /$ day) & $4,847.95 \pm 457.95$ & $3,986.67 \pm 348.94$ & $3,157.65 \pm 375.7$ & $<0.001$ \\
\hline Retinol (ug/day) & $85.9 \pm 16.74$ & $44.15 \pm 8.65$ & $11.83 \pm 12.6$ & 0.001 \\
\hline Thiamin (mg/day) & $1.18 \pm 0.04$ & $1 \pm 0.02$ & $0.8 \pm 0.03$ & $<0.001$ \\
\hline $\begin{array}{l}\text { Riboflavin } \\
\text { (mg/day) }\end{array}$ & $1.14 \pm 0.04$ & $0.9 \pm 0.03$ & $0.67 \pm 0.03$ & $<0.001$ \\
\hline Niacin (mg/day) & $14.67 \pm 0.61$ & $12.85 \pm 0.42$ & $10.74 \pm 0.46$ & $<0.001$ \\
\hline Fiber (g/day) & $8.22 \pm 0.34$ & $7.39 \pm 0.31$ & $5.78 \pm 0.34$ & $<0.001$ \\
\hline Water (g/day) & $966.4 \pm 45.08$ & $721.37 \pm 27.36$ & $504.88 \pm 38.25$ & $<0.001$ \\
\hline
\end{tabular}

Values are presented as mean \pm standard deviation.

${ }^{*} P$-value was obtained from a linear regression model after adjusting for age, gender, region, income, and education level.

dietary patterns. Calcium intake was highest in the balanced pattern, but it critically low in all groups ( $510.58 \pm 21.17$ vs. $496.15 \pm 45.23$ vs. $340.18 \pm 23.75 \mathrm{mg} /$ day). Vitamin C intake was highest in the balanced pattern and sufficient compared with KDRIs at $100 \mathrm{mg}$ /day. However, the imbalanced and very imbalanced patterns were deficient in vitamin C intake ( $110.62 \pm 5.45$ vs. $90.58 \pm 4.46$ vs. $64.45 \pm$ $5.08 \mathrm{mg} /$ day). Intake of other nutrients such as iron, vitamin A, carotene, thiamin, riboflavin, and niacin was highest in the balanced pattern. Sodium intake was excessive in all patterns $(4,590.67 \pm$ 218.57 vs. $4,199.19 \pm 199.99$ vs. $3,504.07 \pm 229.69 \mathrm{mg} /$ day). The ratio of macronutrients (carbohydrates:fats:protein) in the balanced
Table 3. Metabolic syndrome and dietary pattern

\begin{tabular}{|c|c|c|c|c|}
\hline Variable & $\begin{array}{c}\text { Balanced } \\
\text { pattern }(n=497)\end{array}$ & $\begin{array}{c}\text { Imbalanced } \\
\text { pattern }(n=642)\end{array}$ & $\begin{array}{l}\text { Very imbalanced } \\
\text { pattern }(n=483)\end{array}$ & $P^{*}$ \\
\hline WC (cm) & $83.83 \pm 0.59$ & $84.74 \pm 0.56$ & $83.42 \pm 0.72$ & 0.156 \\
\hline HDL cholesterol (mg/dL) & $49.57 \pm 0.77$ & $48.94 \pm 0.80$ & $47.69 \pm 0.90$ & 0.180 \\
\hline $\mathrm{SBP}(\mathrm{mmHg})$ & $132.22 \pm 1.31$ & $134.05 \pm 1.42$ & $131.95 \pm 1.56$ & 0.169 \\
\hline $\mathrm{DBP}(\mathrm{mmHg})$ & $79.15 \pm 0.67$ & $80.16 \pm 0.72$ & $79.44 \pm 0.74$ & 0.368 \\
\hline Triglyceride (mg/dL) & $144.39 \pm 5.18$ & $144.73 \pm 5.97$ & $151.73 \pm 8.32$ & 0.583 \\
\hline Fasting glucose (mg/dL) & $108.24 \pm 1.78$ & $106.73 \pm 1.67$ & $101.56 \pm 1.72$ & 0.001 \\
\hline $\mathrm{HOMA}^{-\mathrm{IR}^{\dagger}}$ & $2.82 \pm 0.12$ & $3.19 \pm 0.20$ & $2.66 \pm 0.19$ & 0.151 \\
\hline
\end{tabular}

Values are presented as mean \pm standard deviation.

${ }^{*} P$-value was obtained from a linear regression model after adjusting for age, gender, region, income, and education level; +HOMA-IR was calculated by fasting insulin ( $\mu \mathrm{lU}$ / $\mathrm{mL}) \times$ fasting plasma glucose $(\mathrm{mg} / \mathrm{dL}) / 405$.

WC, waist circumference; HDL, high-density lipoprotein; SBP, systolic blood pressure; DBP, diastolic blood pressure; HOMA-IR, homeostasis model assessment of insulin resistance.

Table 4. Multivariate-adjusted ORs (95\% CI) for metabolic syndrome and dietary pattern

\begin{tabular}{|c|c|c|c|c|c|}
\hline \multirow[t]{2}{*}{ Variable } & \multirow{2}{*}{$\begin{array}{c}\begin{array}{c}\text { Balanced } \\
\text { pattern } \\
(\mathrm{n}=497)\end{array} \\
\mathrm{OR}\end{array}$} & \multicolumn{2}{|c|}{$\begin{array}{l}\text { Imbalanced pattern } \\
\qquad(\mathrm{n}=642)\end{array}$} & \multicolumn{2}{|c|}{$\begin{array}{l}\text { Very imbalanced pattern } \\
\qquad(\mathrm{n}=483)\end{array}$} \\
\hline & & $\mathrm{OR}(95 \mathrm{Cl} \%)$ & $P$ & $\mathrm{OR}(95 \mathrm{Cl} \%)$ & $P$ \\
\hline $\begin{array}{l}\text { Abdominal } \\
\text { obesity* }\end{array}$ & 1 & 1.104 (0.808-1.509) & 0.532 & $0.875(0.611-1.254)$ & 0.466 \\
\hline $\begin{array}{l}\text { Low HDL } \\
\text { cholesterol }^{\dagger}\end{array}$ & 1 & $1.150(0.832-1.591)$ & 0.396 & 1.339 (0.911-1.968) & 0.137 \\
\hline $\begin{array}{l}\text { Elevated blood } \\
\text { pressure }^{\ddagger}\end{array}$ & 1 & $0.648(0.441-0.952)$ & 0.027 & $0.832(0.545-1.271)$ & 0.394 \\
\hline Elevated TG ${ }^{\S}$ & 1 & $1.288(0.965-1.720)$ & 0.086 & 1.539 (1.057-2.239) & 0.025 \\
\hline $\begin{array}{l}\text { Metabolic } \\
\text { syndrome }\end{array}$ & 1 & $1.005(0.771-1.310)$ & 0.970 & 0.939 (0.667-1.322) & 0.716 \\
\hline
\end{tabular}

All logistic models were adjusted for age, gender, region, income, and education. ${ }^{*}$ Abdominal obesity defined as waist circumference $\geq 90 \mathrm{~cm}$ in men and $\geq 85 \mathrm{~cm}$ in women; ' $\mathrm{L}$ ow HDL cholesterol was defined by $<40 \mathrm{mg} / \mathrm{dL}$ in men and $<50 \mathrm{mg} / \mathrm{dL}$ in women; "Elevated blood pressure was defined by systolic blood pressure $\geq 130 \mathrm{mmHg}$

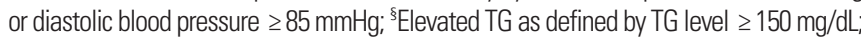
$\mathrm{OR}$, odds ratio; $\mathrm{Cl}$, confidence interval; $\mathrm{HDL}$, high-density lipoprotein; $\mathrm{TG}$, triglyceride.

pattern (\%) was 68.58:16.33:14.55, 75.25:11.61:13.73 in the imbalanced pattern, and 81.15:7.18:11.50 in the very imbalanced pattern.

Table 3 shows the relationships among MetS components and dietary patterns. Fasting glucose was significantly different among the dietary patterns after adjusting for age, gender, region, income, education level. Serum TG levels were slightly higher in the "very imbalanced" pattern $(144.39 \pm 5.18$ vs. $144.73 \pm 5.97$ vs. $151.73 \pm$ $8.32 \mathrm{mg} / \mathrm{dL}$ ) and HDL cholesterol levels were significantly lower $(49.57 \pm 0.77$ vs. $48.94 \pm 0.80$ vs. $47.69 \pm 0.90 \mathrm{mg} / \mathrm{dL})$, whereas se- 
rum fasting blood glucose levels were lowest in the balanced pattern $(108.24 \pm 1.78$ vs. $106.73 \pm 1.67$ vs. $101.56 \pm 1.72 \mathrm{mg} / \mathrm{dL})$.

The multivariate-adjusted ORs (95\% CI) for MetS and dietary patterns are presented in Table 4. Members of the very imbalanced had a 54\% higher likelihood of having hypertriglyceridemia $(P=$ 0.025) compared with the balanced pattern. Members of the imbalanced pattern had a $35 \%$ higher likelihood of having a blood pressure abnormality $(P=0.027)$. Other abnormalities were not associated with dietary patterns.

\section{DISCUSSION}

We identified three different dietary patterns based on nutrient intake in this large, nationally representative study of elderly Koreans. All three patterns seemed to be based on a traditional Korean diet base because each had high consumption of white rice or other grains, various plant-based foods including high kimchi consumption and low total energy and fat intake. ${ }^{16-19}$ There are unique dietary patterns in every country, which could have different influences on the development of chronic disease. ${ }^{7}$ Tortosa et al. ${ }^{20}$ found that a Mediterranean diet is inversely associated with the incidence of MetS; however, these results are not generalizable to Koreans because their eating patterns and disease pathogenesis are different. Other studies have shown that a traditional Korean dietary pattern is associated with a reduced rate of MetS and sarcopenia and specifically a lower incidence of abdominal obesity and IR. ${ }^{18} \mathrm{~A}$ study in adults by Song and Joung ${ }^{17}$ found that members of both the "meat and alcohol" and "Korean healthy" patterns had significantly reduced risk of HDL cholesterol abnormalities compared with the "Korean traditional" pattern. The Korean traditional pattern is high in carbohydrate and vegetable intake and low in fat intake. ${ }^{17}$

We observed that most elderly South Koreans still maintain a traditional dietary pattern including consumption of vegetables, kimchi, eggs, legumes, and seaweed across all three dietary patterns in this study. This indicates that Western dietary trends have not yet emerged among elderly South Koreans. Although, there is a notion that the traditional Korean diet is healthier than a Westernized diet, our findings and others suggest that the traditional Korean diet may actually be responsible for poor nutritional status in some elderly persons. ${ }^{8}$ Changes in family structure and weakened family support systems for the elderly ${ }^{21}$ have led to an increased number of elderly persons living alone, and many of them are at high nutritional risk due to lack of dietary intake, poverty, social isolation, limited mobility, tooth loss, chronic diseases, diarrhea or irregular eating. ${ }^{22}$ In the present study, the very imbalanced pattern comprised $31 \%$ of the study population. This pattern had more than $70 \%$ of its percent daily energy intake solely from white rice and kimchi and beverage consumption was higher than in another two patterns.

Interestingly, there was not a significant difference in carbohydrate intake among the three dietary patterns, but the quality of carbohydrates was different. The very imbalanced pattern obtained $80 \%$ of their energy from carbohydrates primarily in the form of white rice. They had excessive grain intake and insufficient consumptions of fruits. Further research is needed to determine whether a high proportion of total energy obtained from carbohydrates is associated with metabolic diseases. It has been suggested that lower carbohydrate consumption has favorable effects on TG as carbohydrates are metabolized into fat. ${ }^{23}$ Song et al. ${ }^{24}$ studied the diets of 30 - to 65 -year-olds and reported that there was a positive association between white rice intake and cardiovascular disease risk factors. Other studies had similar results. ${ }^{25}$ There are reports that high carbohydrate consumption is associated with obesity and dyslipidemia in adults, including a study in South Korean women. 14,26,27

We also found that the balanced dietary pattern was associated with a lower incidence of metabolic risk. The incidence of hypertriglyceridemia was 54\% in the very imbalanced diet pattern. Compared with the balanced pattern, the very imbalanced pattern had a significantly increased risk of having TG abnormality and reduced risk of fasting blood glucose abnormality. These findings support the notion that increased white rice consumption and kimchi as a meal can lead to poor nutritional status and malnutrition in the elderly.

Another interesting finding was that protein intake in the very imbalanced group $(0.78 \mathrm{~g} / \mathrm{kg} /$ day $)$ was deficient compared with KDRIs. However, there are several studies suggesting that even 1.0 $\mathrm{g} / \mathrm{kg} /$ day is not sufficient for the elderly, and they recommend 1.0 $1.2 \mathrm{~g} / \mathrm{kg} /$ day or more. ${ }^{5,26,28}$ Hannan et al. ${ }^{29}$ emphasized the importance of both total and animal protein intake in the elderly. Therefore, elderly Koreans whose diets are traditionally rich in plant foods 
like soybeans and soy-based foods need to increase their consumption of animal protein and milk. It has been shown that increased serum insulin-like growth factor 1 influenced by milk-based protein is the most important mediator of muscle growth and repair. ${ }^{30} \mathrm{Oh}$ et al. ${ }^{18}$ found that a diet rich in protein, omega 3 , vitamin $\mathrm{D}$, calcium, and vitamin $\mathrm{C}$ is beneficial in stimulating protein synthesis and also decreasing inflammatory cytokines. Protein, vitamin D, and calcium intake was low in the traditional Korean pattern in that study. ${ }^{18}$ Protein is also an important nutrient for the elderly because it has been linked with clusters of cardiovascular risk factors and body composition changes in aging. ${ }^{1}$ Similar findings were reported on the association between sarcopenia and MetS $\mathrm{S}^{2,3}$, and core causes are IR and chronic low-grade inflammatory state.

Research on the relationship between metabolic abnormalities, protein consumption and muscle mass found an association between loss of muscle in the elderly and insufficient protein intake. ${ }^{5}$ However, this issue has not been fully studied in elderly Koreans. Although the traditional Korean diet has many healthy components, we must focus on the elderly with imbalanced and very imbalanced dietary patterns to prepare for a super aging society. One study reported that there are unique features to traditional dietary patterns in Korea but these patterns have undergone some modifications influenced by Western diets. ${ }^{18}$ The same study reported that dietary pattern was associated with MetS and body composition. When compared with the traditional Korean pattern, the meat \& alcohol pattern was associated with a $50 \%$ increased risk of obesity, and the Westernized Korean pattern was associated with a $74 \%$ increased risk of sarcopenia. ${ }^{18}$ The traditional Korean pattern showed protein deficiency and lower muscle mass than other patterns. ${ }^{18}$ High carbohydrate intake in U.S. adults had a beneficial effect with regard to lower rates of obesity but had negative effects with regard to lower HDL cholesterol and higher TG. ${ }^{30}$

The strength of the present study was that it is nationally representative as it was performed in elderly South Koreans. Furthermore, this is the first epidemiologic study in elderly South Koreans focused on risk factors for the MetS and dietary patterns classified based on nutrient intake. The results of the present study will yield a new understanding of dietary patterns and inform early intervention using appropriate nutrition education tailored toward elderly South Koreans.
Several limitations should be considered in the interpretation of our findings. Our findings cannot be generalized to other populations because the method of dietary classification (and naming) was relatively subjective. The study of dietary patterns in the elderly in various ways is necessary in further studies. Another limitation is that KNHANES collected data based on a single instance of 24hour recall, which might not represent usual daily intake. However, at the population level, 24-hour recall can be used as a surrogate measure of usual intake. All participants in the present study were relatively healthy because KNHANES did not include hospitalized people; therefore, the mean values of MetS and its risk factors may have been underestimated. The cross-sectional design of our study limits causal inference between dietary patterns and metabolic risk factors. These results need to be confirmed with additional, longitudinal data. Lastly, we could not control for all epigenetic influences; thus, these results need to be confirmed by additional study with longitudinal data to increase generalizability of the results.

In conclusion, we observed that most elderly South Koreans still maintain a traditional dietary pattern, which previously had been considered a healthy diet, but has some unhealthy components. The current findings indicate that elderly South Koreans may be nutritionally imbalanced due in part to high carbohydrate consumption. Although there was not a significant association between the MetS and dietary patterns, there was a significantly higher risk of TG abnormality in the very imbalanced group. Management of the elderly in this pattern is an important and urgent issue for the National Health Promotion. Our findings should draw more attention to the effect of the excess or shortage of nutrient components on MetS in the elderly.

\section{CONFLICTS OF INTEREST}

The authors declare no conflict of interest.

\section{REFERENCES}

1. Cornier MA, Dabelea D, Hernandez TL, Lindstrom RC, Steig AJ, Stob NR, et al. The metabolic syndrome. Endocr Rev 2008; 29:777-822.

2. Stump CS, Henriksen EJ, Wei Y, Sowers JR. The metabolic 
syndrome: role of skeletal muscle metabolism. Ann Med 2006; 38:389-402.

3. Scott D, Park MS, Kim TN, Ryu JY, Hong HC, Yoo HJ, et al. Associations of low muscle mass and the metabolic syndrome in Caucasian and Asian middle-aged and older adults. J Nutr Health Aging 2016;20:248-55.

4. Ahluwalia N, Andreeva VA, Kesse-Guyot E, Hercberg S. Dietary patterns, inflammation and the metabolic syndrome. Diabetes Metab 2013;39:99-110.

5. Volpi E, Campbell WW, Dwyer JT, Johnson MA, Jensen GL, Morley JE, et al. Is the optimal level of protein intake for older adults greater than the recommended dietary allowance? J Gerontol A Biol Sci Med Sci 2013;68:677-81.

6. Kant AK. Dietary patterns and health outcomes. J Am Diet Assoc 2004;104:615-35.

7. Sánchez-Villegas A, Delgado-Rodríguez M, Martínez-González MA, De Irala-Estévez J; Seguimiento Universidad de Navarra group. Gender, age, socio-demographic and lifestyle factors associated with major dietary patterns in the Spanish Project SUN (Seguimiento Universidad de Navarra). Eur J Clin Nutr 2003;57:285-92.

8. Park MY, Kim GR, Lee DJ, Kim JM, Park PS. A survey of food and nutrient intakes of the aged people in rural area, Gyeongbuk Yecheon. J Nutr Health 2006;39:58-73.

9. Kwon SH. Status of under- \& over-nutrition in Korea National Health and Nutrition Examination Survey (KNHANES) [Internet]. Cheongju: Korea Centers for Disease Control and Prevention; 2014 [cited 2018 Dec 5]. Available from: http:// www.cdc.go.kr/CDC/info/CdcKrInfo0301.jsp?menuIds= HOME001-MNU1154-MNU0005-MNU0037\&q type=\&y ear $=2014 \&$ cid $=60592 \&$ pageNum $=$

10. Szarc vel Szic K, Ndlovu MN, Haegeman G, Vanden Berghe W. Nature or nurture: let food be your epigenetic medicine in chronic inflammatory disorders. Biochem Pharmacol 2010;80: 1816-32.

11. Robertson KD. DNA methylation and human disease. Nat Rev Genet 2005;6:597-610.

12. Kim J, Jo I, Joung H. A rice-based traditional dietary pattern is associated with obesity in Korean adults. J Acad Nutr Diet 2012;112:246-53.
13.Jang JY, Kim MJ, Han JS. A study on food frequency, dietary habits and nutrition knowledge of the elderly who intake high sodium. J Korean Soc Food Sci Nutr 2009;38:1362-72.

14. Suh YS, Park MS, Chung YJ. An evaluation of chronic disease risk based on the percentage of energy from carbohydrates and the frequency of vegetable intake in the Korean elderly: using the 2007-2009 Korea National Health and Nutrition Examination Survey. Korean J Community Nutr 2015;20:41-52.

15. Lee JE, Kim JH, Son SJ, Ahn Y, Lee J, Park C, et al. Dietary pattern classifications with nutrient intake and health-risk factors in Korean men. Nutrition 2011;27:26-33.

16. Song Y, Joung H, Engelhardt K, Yoo SY, Paik HY. Traditional v. modified dietary patterns and their influence on adolescents nutritional profile. Br J Nutr 2005;93:943-9.

17. Song Y, Joung H. A traditional Korean dietary pattern and metabolic syndrome abnormalities. Nutr Metab Cardiovasc Dis 2012;22:456-62.

18. Oh C, Jho S, No JK, Kim HS. Body composition changes were related to nutrient intakes in elderly men but elderly women had a higher prevalence of sarcopenic obesity in a population of Korean adults. Nutr Res 2015;35:1-6.

19. Kim SH, Oh SY. Cultural and nutritional aspects of traditional Korean diet. World Rev Nutr Diet 1996;79:109-32.

20. Tortosa A, Bes-Rastrollo M, Sanchez-Villegas A, Basterra-Gortari FJ, Nuñez-Cordoba JM, Martinez-Gonzalez MA. Mediterranean diet inversely associated with the incidence of metabolic syndrome: the SUN prospective cohort. Diabetes Care 2007; 30:2957-9.

21. Park MJ. The study of daily life of aged women living alone who receive the National Basic Livelihood Security Program. Health Soc Welf Rev 2010;30:62-91.

22. Visvanathan R. Under-nutrition in older people: a serious and growing global problem! J Postgrad Med 2003;49:352-60.

23. Minehira K, Vega N, Vidal H, Acheson K, Tappy L. Effect of carbohydrate overfeeding on whole body macronutrient metabolism and expression of lipogenic enzymes in adipose tissue of lean and overweight humans. Int J Obes Relat Metab Disord 2004;28:1291-8.

24. Song S, Lee JE, Song WO, Paik HY, Song Y. Carbohydrate intake and refined-grain consumption are associated with meta- 
bolic syndrome in the Korean adult population. J Acad Nutr Diet 2014;114:54-62.

25. Nanri A, Mizoue T, Noda M, Takahashi Y, Kato M, Inoue M, et al. Rice intake and type 2 diabetes in Japanese men and women: the Japan public health center-based prospective study. Am J Clin Nutr 2010;92:1468-77.

26. Yang EJ, Chung HK, Kim WY, Kerver JM, Song WO. Carbohydrate intake is associated with diet quality and risk factors for cardiovascular disease in U.S. adults: NHANES III. J Am Coll Nutr 2003;22:71-9.

27. Park SH, Lee KS, Park HY. Dietary carbohydrate intake is associated with cardiovascular disease risk in Korean: analysis of the third Korea National Health and Nutrition Examination Survey (KNHANES III). Int J Cardiol 2010;139:234-40.

28. Maggio M, De Vita F, Lauretani F, Buttò V, Bondi G, Cattabi- ani C, et al. IGF-1, the cross road of the nutritional, inflammatory and hormonal pathways to frailty. Nutrients 2013;5:4184205.

29. Hannan MT, Tucker KL, Dawson-Hughes B, Cupples LA, Felson DT, Kiel DP. Effect of dietary protein on bone loss in elderly men and women: the Framingham Osteoporosis Study. J Bone Miner Res 2000;15:2504-12.

30. National Cholesterol Education Program (NCEP) Expert Panel on Detection, Evaluation, and Treatment of High Blood Cholesterol in Adults (Adult Treatment Panel III). Third Report of the National Cholesterol Education Program (NCEP) Expert Panel on Detection, Evaluation, and Treatment of High Blood Cholesterol in Adults (Adult Treatment Panel III) final report. Circulation 2002;106:3143-421. 